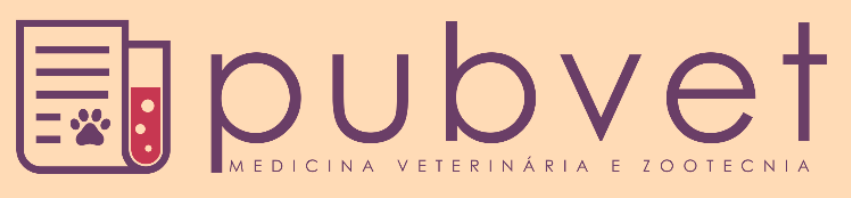

https://doi.org/10.31533/pubvet.v16n01a1004.1-7

\title{
Incidência de helmintos gastrointestinais em bezerras leiteiras de 6 a 12 meses no município de Medianeira, Paraná
}

\author{
Claudia Lian da Silva1, Caroline Pereira da $\operatorname{Costa}^{2}$ (\$) \\ ${ }^{1}$ Dicente do Curso de Medicina Veterinária pelo Centro Universitário Dinâmica das Cataratas/ Foz do Iguaçu, PR, Brasil. \\ ${ }^{2}$ Docente do Centro Universitário Dinâmica das Cataratas / Foz do Iguaçu, PR, Brasil. \\ Autor para correspondência, E-mail: claudia_lian@hotmail.com
}

Resumo. Os helmintos gastrointestinais estão entre os principais agentes etiológicos que afetam o desenvolvimento dos rebanhos bovinos, aumentam a taxa de mortalidade dos animais e geram prejuízos econômicos aos pecuaristas. O presente estudo tem como objetivo identificar a incidência de ovos de helmintos em bezerras leiteiras de 6 a 12 meses de idade, do município de Medianeira, estado do Paraná. As doze propriedades foram escolhidas de forma aleatória. Foram coletadas amostras de 61 animais e examinadas através da técnica de OPG, ovos por gramas de fezes. Os produtores responderam a um questionário relativo ao tratamento e protocolo de everminação. Das 61 amostras coletadas, $28(45,9 \%)$ apresentaram-se negativas para a presença de ovos e 33 amostras $(54,1 \%)$ apresentaram-se positivas para a presença de ovos. Sete das propriedades utilizaram Doramectina na everminação das bezerras, três propriedades utilizaram Ripercol, apenas uma propriedade utilizou Endazol, e uma delas nunca havia desverminado animais jovens. Os dados obtidos evidenciam que o número de vermifugações ao ano justificam a quantidade de ovos encontrados nas fezes e as amostras positivadas para o parasitismo gastroentérico. As propriedades que realizaram o manejo de everminação seis vezes no ano, obtiveram animais livres de ovos de helmintos.

Palavras-chave: Bezerras, controle estratégico, distúrbios, helmintos

\section{Incidence of gastrointestinal helminths in dairy heifers aged 6 to 12 months in the city of Medianeira, Paraná}

\begin{abstract}
Gastrointestinal helminths are among the main etiological agents that affect the development of cattle herds, increase the mortality rate of animals and generate economic losses for farmers. This study aims to identify the incidence of helminth eggs in dairy heifers from 6 to 12 months of age, in the municipality of Medianeira, state of Paraná. The twelve properties were chosen at random. Samples from 61 animals were collected and examined using the OPG technique, eggs per gram of feces. Producers answered a questionnaire regarding the treatment and protocol of everting. Of the 61 samples collected, $28(45.9 \%)$ were negative for the presence of eggs and 33 samples $(54.1 \%)$ were positive for the presence of eggs. Seven of the farms used Doramectin in the evergreening of heifers, three farms used Ripercol, only one farm used Endazol, and one of them had never deverminated young animals. The data obtained show that the number of vermifuges per year justifies the number of eggs found in the feces and the positive samples for gastroenteric parasitism. The properties that performed the management of eventuation six times a year, obtained animals free of helminth eggs.
\end{abstract}

Keywords: Heifers, strategic control, disturbances, helminths 


\section{Introdução}

A pecuária leiteira é uma das principais atividades da economia brasileira com relevante papel no suprimento de alimentos e geração de renda. A produção de leite é uma das atividades mais representativas da economia nacional. Tratando-se do valor bruto da produção pecuária, a cadeia produtiva do leite é a segunda em geração de renda, $\mathrm{R} \$ 45,8$ bilhões em 2017 , ficando atrás somente da carne bovina (CNA, 2020).

O Brasil é o terceiro maior produtor mundial de leite, atrás apenas dos Estados Unidos e da Índia, segundo dados da Food and Agricultural Policy Research Institute (FAPRI, 2020). No Brasil, cerca de $47 \%$ da produção de leite é proveniente de pequenos produtores (Assis et al., 2005; Siqueira \& Zoccal, 2012). A produção leiteira no Brasil é composta por grande parte de produtores de pequena e média escala, ocorre uma falha no investimento, prejudicando o desenvolvimento da atividade, uma vez que não adotadas as boas práticas de higiene e a falta de sanidade dos animais e deficiências no manejo, impactam diretamente no produto final, tempo de prateleira do leite e derivados (Nero et al., 2009; Prado, 2004).

A produtividade e o desempenho da bovinocultura são influenciados negativamente por inúmeros fatores, entre eles destacam-se as parasitoses gastrintestinais (Bert E Stromberg et al., 2012). O controle de parasitos é um importante fator, uma vez que os parasitos causam grandes perdas econômicas devido à queda de produtividade e transmissão de patógenos, podendo acarretar na morte dos animais (Delgado et al., 2009; Ronda et al., 2009).

Sendo assim, esse trabalho tem como objetivo avaliar a incidência de ovos de helmintos gastrointestinais, em bezerras leiteiras de 6 a 12 meses de idade, comparando os resultados obtidos com os manejos de vermifugações em diferentes propriedades do município de Medianeira, região oeste do estado do Paraná.

\section{Materiais e métodos}

O estudo foi realizado em propriedades rurais produtoras de leite na cidade de Medianeira, localizada na região Oeste do estado do Paraná. O município de Medianeira conta com um rebanho de 26.179 cabeças de gado, entre bovinos de corte e leite e 1.119 produtores rurais. Dentre estes, 215 dos produtores têm como a atividade exclusiva a produção de leite com um rebanho de 3.474 bovinos. Foram visitadas doze propriedades produtoras de leite durante a realização do trabalho, as propriedades foram escolhidas conforme solicitação de atendimento veterinário durante o estágio extracurricular. Ao todo foram coletadas amostras de 61 animais, com idade entre seis a 12 meses de idade, sendo 52 animais da raça Holandesa, 7 animais da raça Jersey e 2 mestiças. A análise das amostras foi realizada na empresa Center Pet, também localizada na cidade de Medianeira, pela técnica de Mc Master, desenvolvida por Gordon \& Whitlock (1939) que avalia quantitativamente o número de ovos por gramas de fezes. No mesmo dia da coleta os produtores responderam a um questionário, de resposta curta, referente aos fármacos e doses utilizadas para everminação e frequência das aplicações no ano.

Para realização da coleta de amostras e posteriormente, das análises, foram utilizados os seguintes materiais: amostras de fezes, solução salina saturada, peneiras, pipeta de Pasteur, câmara de Mc Master, microscópio óptico, proveta de $100 \mathrm{ml}$, becker de vidro, copo descartável, saco plástico transparente, seringa de $20 \mathrm{ml}$, colher de plástico, recipiente de plástico com tampa e caixa de isopor. Para a coleta das fezes foram utilizados sacos plásticos limpos enluvados na mão direita do coletor, que serviram como luva para coleta. As fezes foram retiradas diretamente da ampola retal dos animais. Após a captação das fezes, foram acondicionadas em recipientes de plástico com tampa, logo em seguida foram identificadas e armazenadas em uma caixa de isopor com gelo até a chegada no local de análise.

Após a chegada no laboratório, as amostras foram retiradas do gelo e com o auxílio de uma colher de plástico foram inseridas em uma seringa com capacidade de $20 \mathrm{ml}$, que teve seu bico cortado para facilitar a entrada da amostra. Na seringa, foram preenchidos $2 \mathrm{ml}$ da amostra. Após a mensuração de 2 $\mathrm{ml}$ da amostra na seringa, dispensou-se o conteúdo em um copo plástico descartável. Com auxílio de uma proveta foram obtidos $28 \mathrm{ml}$ de solução salina saturada e está foi adicionada ao copo plástico contendo a amostra, seguida pela diluição das fezes na solução salina por homogeneização. 
Após a diluição, o conteúdo do copo foi peneirado e transferido para um Becker de $250 \mathrm{ml}$. Em seguida, o líquido obtido foi homogeneizado e coletado com a pipeta de Pasteur para o correto preenchimento de um lado da câmara de Mc Master, repetindo o mesmo processo para o segundo lado da câmara, evitando a formação de bolhas. A flutuação dos ovos ocorreu rapidamente após alguns minutos, e então foi analisado microscopicamente na objetiva de menor aumento (4x), em seguida foi observado na objetiva de 10x. O Microscópio óptico utilizado foi o modelo K55-BA, da marca Olen. Foram observados cada quadrante da câmara, os ovos encontrados dos dois lados da câmara foram contabilizados conjuntamente.

\section{Resultados}

Os dados obtidos através do questionário realizado aos proprietários dos animais junto aos resultados obtidos no OPG foram inseridos na tabela 1. Primeiramente foram listadas as informações oriundas de 7 propriedades (A-G) que utilizavam a Doramectina como fármaco de escolha na everminação de animais jovens, posteriormente foram listadas as informações oriundas de 3 propriedades que utilizam o Ripercol (H-J), seguido do Endazol e ainda de uma única propriedade que não evermina animais jovens e não soube informar o fármaco utilizado em animais adultos (K-L). As informações obtidas através do questionário realizado juntamente com os produtores rurais foram conflitadas com os resultados obtidos através das análises laboratoriais de OPG e estas, por sua vez, foram adicionadas a um gráfico de barras, que evidencia informações relevantes em relação a frequência de everminações do plantel de bezerras e a quantidade de amostras positivas para ovos, seguida pela quantidade deles. As informações relativas as propriedades que utilizam a Doramectina como fármaco de escolha foram inseridas no gráfico 1, enquanto que as informações referentes as propriedades que utilizam o Ripercol e o Endazol estão inseridas no gráfico 2.

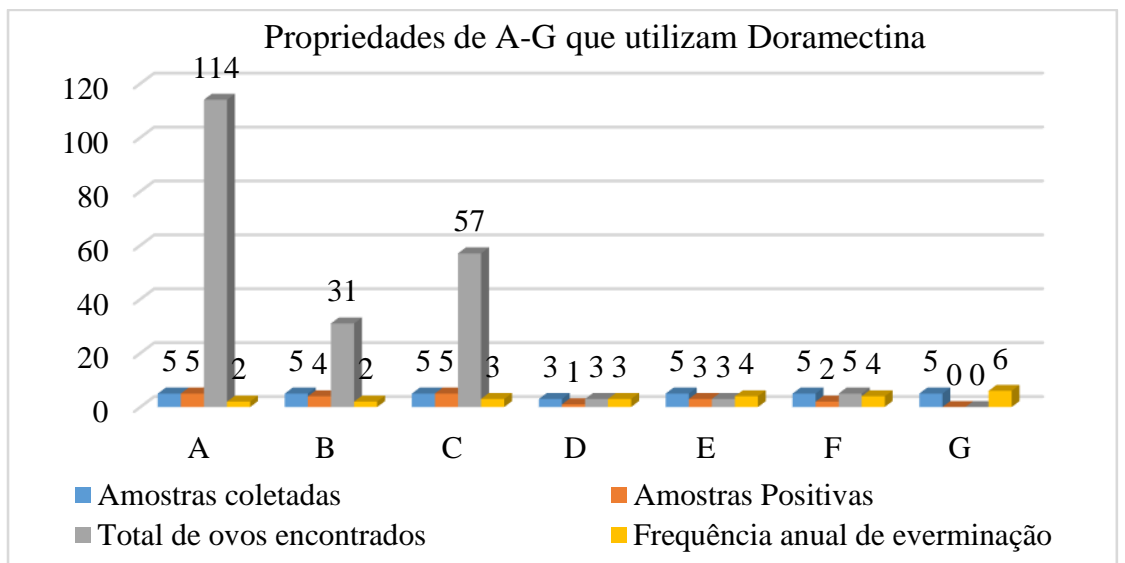

Gráfico 1. Resultados referentes ao número de amostras coletadas e positivadas, total de ovos encontrados na análise de OPG e frequência anual de everminação das propriedades que utilizam a Doramectina como fármaco de eleição.

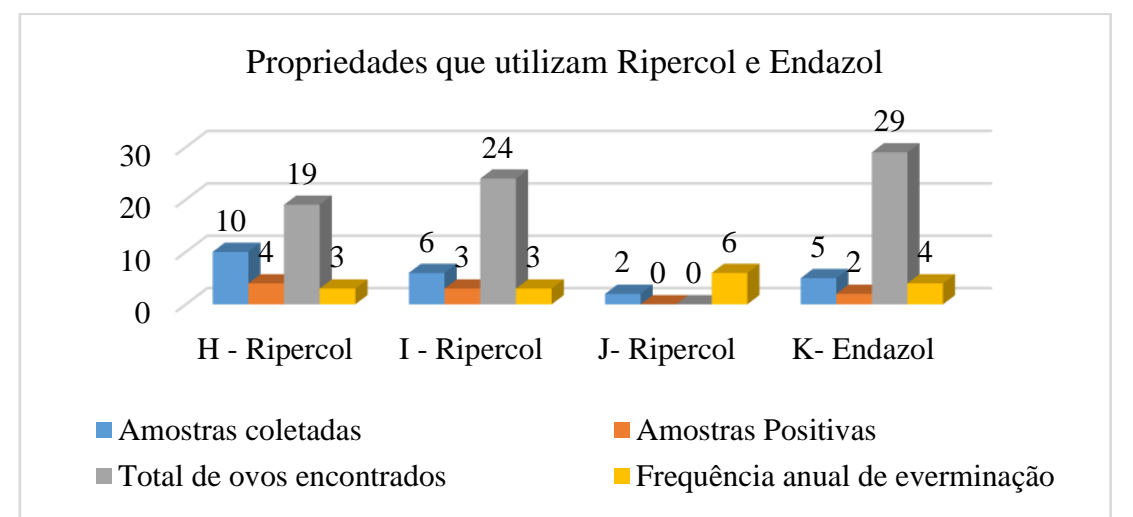

Gráfico 2. Resultados referentes ao número de amostras coletadas e positivadas, total de ovos encontrados na análise de OPG e frequência anual de everminação das propriedades que utilizam o Ripercol e o Endazol como fármacos de eleição. 


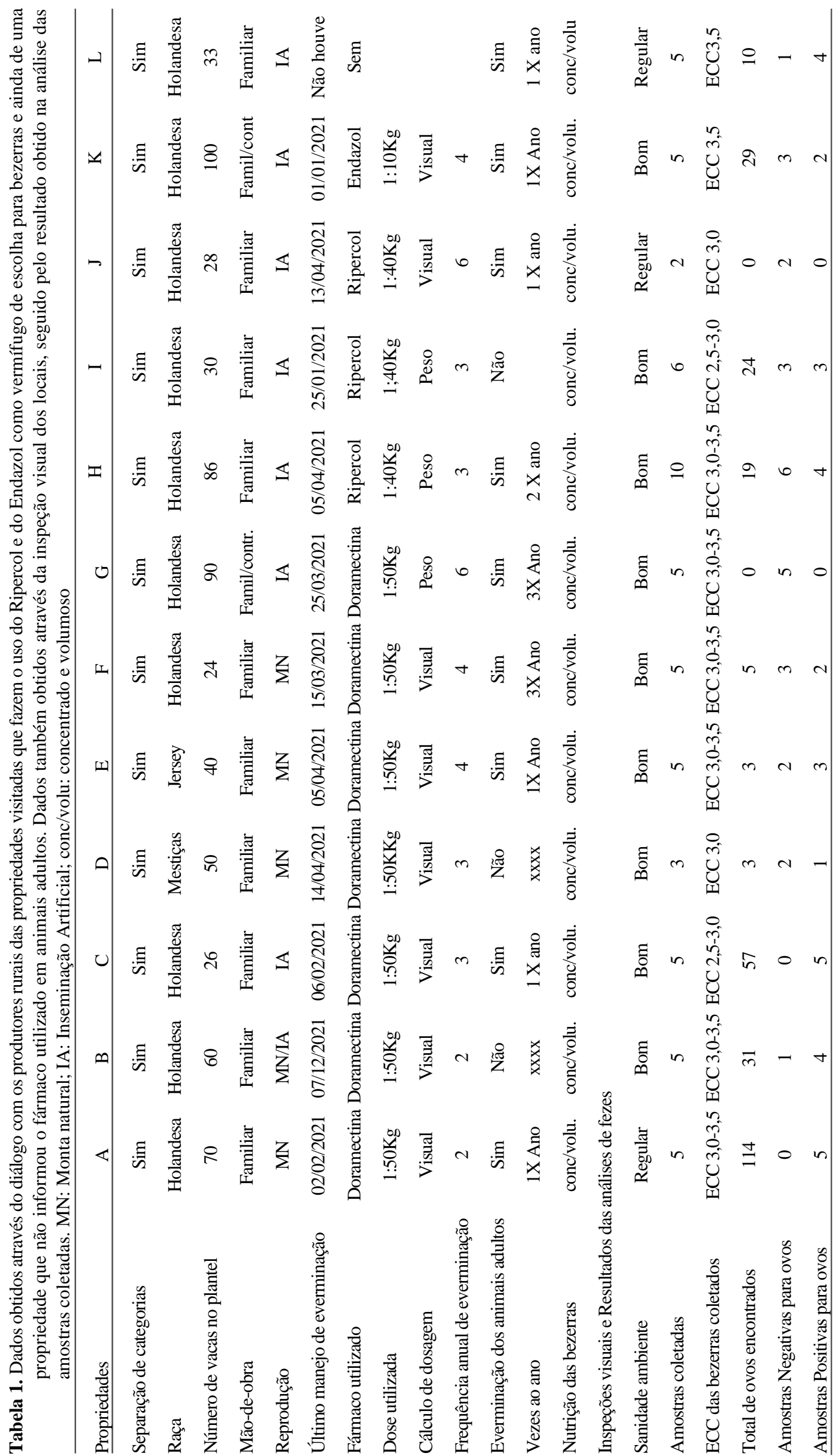


No período de abril a junho do ano de 2021, foram examinadas fezes de 61 bezerras, 28 amostras $(45,9 \%)$ apresentaram-se negativas para a presença de ovos de helmintos e 33 amostras $(54,1 \%)$ apresentaram-se positivas para a presença de ovos. Foram contabilizados 295 ovos de parasitas entre as 33 amostras que apresentaram algum tipo de parasitismo gastrointestinal. Das doze propriedades coletadas, nove faziam uso de mão de obra familiar e três contavam com mão de obra familiar e contratada. Todas as propriedades realizavam separação de lotes por categoria de animais. Sete das propriedades utilizaram Doramectina na everminação das bezerras, três propriedades utilizaram Ripercol, apenas uma propriedade utilizou Endazol e uma delas nunca havia desverminado animais jovens.

Os dados obtidos evidenciam que o número de vermifugações ao ano justificam a quantidade de ovos encontrados nas fezes e as amostras positivadas para o parasitismo gastro entérico. Nas propriedades que fizeram uso da Doramectina, a menor frequência anual de everminação foi de duas administrações ao ano, enquanto a maior frequência anual foi de seis vezes ao ano. Nas cinco amostras coletadas da propriedade A, todas testaram positivo para a presença de ovos, sendo encontrados 114 unidades de ovos nas fezes. A propriedade $\mathrm{G}$, contou também com cinco amostras coletadas. Contudo, nenhuma amostra apresentou ovos. A propriedade A realiza duas vermifugações anuais, enquanto a propriedade $\mathrm{G}$ realiza seis.

Resultados semelhantes são evidenciados na propriedade $\mathrm{J}$, que também realiza seis vermifugações anuais e não exibiu presença de ovos nas amostras coletadas. Essa informação parece evidenciar que a escolha do fármaco não justifica a presença de ovos, mas a frequência de administração anual da droga nos animais sim. Não foram realizadas análises estatísticas em decorrência do grande número de variáveis e o pequeno número amostral.

\section{Discussão}

De acordo com os resultados obtidos, das 61 amostras examinadas, 28 (45,9\%) das amostras apresentaram-se negativos e $33(54,1 \%)$ revelaram infecções por algum tipo de parasita gastrointestinal. A lactonas macrocíclicas (Doramectina), fármaco utilizado por sete $(58,3 \%)$ das propriedades avaliadas, apresentou nível de eficiência satisfatório para aquelas que realizaram aplicações seis vezes no ano, assim como levamisol (Ripercol) utilizado por três $(25,0 \%)$ das propriedades e albendazol (Endazol) utilizado por $1(8,3 \%)$. As propriedades que utilizaram lactonas macrocíclicas, levamisole e albendazol com frequência inferior a seis vezes no ano, apresentaram resultado positivo para parasitoses gastrointestinais. Girão \& Leal (2000), em rebanhos de Teresina- PI, analisaram 1.020 amostras de fezes, $573(56,0 \%)$ apresentaram resultado positivo para parasitas. O controle de verminose foi feito com a utilização de anti-helmínticos à base de levamisole, oxibendazole ou ivermectina. Pereira (2011), em um estudo em relação a práticas de controle e prevalências de helmintos gastrointestinais em bovinos leiteiros em 40 propriedades rurais de Pindamonhangaba, SP, com 356 bezerros, evidenciou que, 66,8\% dos animais apresentaram contagem de OPG positiva. Os produtos mais utilizados foram as ivermectinas $(50,0 \%)$, levamisole $(37,5 \%)$ e albendazole (12,5\%). A maioria dos entrevistados $(52,5 \%)$ declarou tratar os animais apenas na estação seca do ano, entre maio e agosto.

Em mesorregiões de Caparaó, Espirito Santo, onde foram visitadas 51 propriedades, coletadas 173 fezes de bezerros e $120(69,36 \%)$ dos bezerros avaliados apresentaram diagnóstico positivo ao exame de fezes. No controle químico das parasitoses, os produtos à base de ivermectina foram citados por $62,0 \%$ dos proprietários e a vermifugação ocorreu menos de três vezes ao ano, em $46 \%$ das propriedades (Repossi Júnior et al., 2008). Repossi Júnior et al. (2006), em um estudo semelhante no município de Alegre - ES, constataram que em todas as amostras houve resultados positivos para parasitas. A ivermectina foi o princípio ativo mais citado; porém, alguns proprietários citaram o também o albendazol. Em relação ao esquema de vermifugação estabelecido $(83,3 \%)$ das fazendas estudadas por eles, apresentarem um protocolo com dose entre setembro e outubro e repetição entre março e abril, ou seja, duas vezes no ano. Souza et al. (2008), durante a realização de estudos no estado em Santa Catarina, observaram que a maioria dos proprietários não tem informações precisas sobre a frequência de tratamentos e dos anti-helmínticos utilizados. Em estudos nos rebanhos leiteiros realizados por Charles \& Furlong (1996) e Delgado et al. (2009) pode ser observado que os anti-helmínticos mais utilizados por pecuaristas brasileiros são os pertencentes à classe das lactonas macrocíclicas (ivermectina, 
doramectina, abamectina e moxidectina), seguido dos imidazotiazóis (levamisol) e benzimidazóis (albendazol).

Quanto as medidas adotadas pelos produtores no presente estudo, para controle das verminoses, foram relatadas manejos de duas a seis vezes ao ano. As propriedades que realizaram o manejo seis vezes no ano, sendo as aplicações nos meses de janeiro, março, maio, julho, setembro e novembro apresentam níveis satisfatórios, com $100 \%$ de eficiência do fármaco e $0 \%$ de presença de parasitas. Percebe-se que o fármaco de eleição não interfere no controle dos helmintos, mas sim a frequência de aplicação do medicamento. Chagas et al. (2008) relatam que a everminação dos animais no início, no meio e no fim da época seca, se configura com uma excelente metodologia de controle de parasitas, de forma econômica e eficiente. Além dessas três vermifugações, uma quarta aplicação, no período das águas, em dezembro, completará essa estratégia. Bianchin \& Honer (1995) recomendam para animais em crescimento, até 24 meses de idade, cinco vermifugações por ano, três na época seca (julho, setembro e novembro) e duas em épocas de chuvas (fevereiro e abril).

Bianchin \& Honer (1995) relatam que, independentemente da quantidade de doses anuais recomendadas ou utilizadas no campo empiricamente, muitas vezes, a observação de elevados padrões de eficácia de produtos antiparasitários podem estar relacionada com a espécie de nematódea presente, devido às variações quanto à susceptibilidade natural dos helmintos aos anti-helmínticos. A ausência de programas estratégicos geralmente resulta na utilização de anti-helmínticos de acordo com a conveniência do produtor, que pode ter pouco ou nenhum impacto na população de parasitos (Stromberg \& Averbeck, 1999). São diversos os protocolos de everminação realizados pelos produtores, variando muito de região para região, uma vez que, devem ser levados em consideração fatores climáticos e a sensibilidade dos animais. Porém, a maioria dos produtores desconhecem o ciclo dos parasitas, sem um controle estratégico, realizam aplicações aleatórias durante o ano, resultando em um controle ineficiente dos parasitas, acarretando prejuízos à sanidade do rebanho, financeiros e desperdício de antihelmínticos.

Os resultados obtidos no presente estudo corroboram com os dados citados pela literatura, evidenciando a implicação da quantidade de administrações de antiparasitários, principalmente de antihelmínticos em bezerras, por se tratar de um acometimento comum a esses animais. A composição do fármaco anti-helmíntico parece não influenciar nos resultados, visto que as amostras com maior e menor número de ovos de helmintos foram coletadas de propriedades distintas e que utilizaram a mesma composição para everminação.

\section{Conclusão}

A presença de ovos de helmintos nas fezes de bezerras é interferida diretamente pela frequência de administração anual das drogas anti-helmínticas nos animais e não pelo fármaco de eleição. Os dados obtidos no presente estudo corroboram com as informações supracitadas pela literatura, evidenciando a importância do estabelecimento de manejos de everminação consistentes, controlados e padronizados na bovinocultura.

\section{Referências bibliográficas}

Assis, A. G., Stock, L. A., Campos, O. F., Gomes, A. T., Zoccal, R., \& Silva, M. R. (2005). Sistemas de produção de leite no Brasil. Embrapa Gado de Leite-Circular Técnica, 1, 1-6.

Bianchin, I., \& Honer, M. R. (1995). Verminose bovina: ocorrencia e controle estrategico. In Embrapa Gado de Corte-Séries Anteriores. Campo Grande: EMBRAPA-CNPGC, 1995.

Chagas, A. C. S., Vieira, L. S., Freitas, A. R., Araújo, M. R. A., Araújo-Filho, J. A., Araguão, W. R., \& Navarro, A. M. C. (2008). Anthelmintic efficacy of neem (Azadirachta indica A. Juss) and the homeopathic product Fator Vermes® in Morada Nova sheep. Veterinary Parasitology, 151(1), 6873.

Charles, T. P., \& Furlong, J. (1996). A survey of dairy cattle worm control practices in southeast Brazil. Veterinary Parasitology, 65(1-2), 65-73. https://doi.org/10.1016/0304-4017(96)00949-1. 
CNA. Confederação da Agricultura e Pecuária do Brasil. (2020). Pesquisa Pecuária Municipal (PPM) 2019: crescimento de todas as atividades englobadas na pesquisa em relação a 2018. Superintendência da CNA.

Delgado, F. E. F., Lima, W. dos S., Cunha, A. P., Bello, A. C. P. P., Domingues, L. N., Wanderley, R. P. B., Leite, P. V. B., \& Leite, R. C. (2009). Verminoses dos bovinos: percepção de pecuaristas em Minas Gerais, Brasil. Revista Brasileira de Parasitologia Veterinária, 18, 29-33. https://doi.org/10.4322/rbpv.01803005.

FAPRI. (2020). Food and Agricultural Policy Research Institute. Food and Agricultural Policy Research Institute; Iowa State University and University of Missouri-Columbia.

Girão, E. S., \& Leal, J. A. (2000). Ocorrência e controle de verminose gastrintestinais em bezerros. Embrapa Meio-Norte-Artigo Em Anais de Congresso, 188-190.

Gordon, H. M., \& Whitlock, H. V. (1939). A new technique for counting nematode eggs in sheep faeces. Journal of the Council for Scientific and Industrial Research, 12(1), 50-52.

Nero, L. A., Vicosa, G. N., \& Pereira, F. E. V. (2009). Microbiological quality of milk determined by production characteristics. Ciência e Tecnologia de Alimentos, 29(2), 386-390. https://doi.org/10.1590/s0101-20612009000200024.

Pereira, J. R. (2011). Práticas de controle e prevalência de helmintos gastrintestinais parasitos de bovinos leiteiros em Pindamonhangaba, São Paulo, Brasil. Revista de Ciências Agroveterinárias, 10(1), 1622.

Prado, I. N. (2004). Conceitos sobre a produção com qualidade de carne e leite (Vol. 1). Eduem.

Repossi Júnior, P. F., Barcellos, M. P., Trivilin, L. O., Martins, I. V. F., \& Silva, P. (2006). Prevalência e controle das parasitoses gastrintestinais em bezerros de propriedades leiteiras no município de Alegre, Espirito Santo. Revista Brasileira de Parasitologia Veterinária, 15(4), 147-150.

Repossi Júnior, P. F., Demoner, L. C., Avelar, B. R., Nunes, L. C., Donatele, D. M., \& Martins, I. V. F. (2008). Estudo parasitológico em bovinos leiteiros da microrregião do Caparaó, Espírito Santo, Brasil Parasitological study in dairy cattle of Caparaó microregion, Espírito Santo State, Brazil. Ciências Veterinárias, CIII, 151-156.

Ronda, J. B., Caetano, M. V., Carmo Panetto, J. C., Bittar, E. R., Bittar, J. F. F., Arduino, G. de G. C., \& Pereira, W. A. B. (2009). Influência de parasitas gastrointestinais no ganho de pesos de bezerros nelore lemgruber na fase de recria. Ciência Animal Brasileira, 1, 654-659. https://doi.org/10.5216/cab.v1i0.7879.

Siqueira, K. B., \& Zoccal, R. (2012). Panorama do leite. Boletim Eletrônico Mensal. Embrapa Gado de Leite, 6(73).

Souza, A. P., Ramos, C. I., Bellato, V., Sartor, A. A., \& Schelbauer, C. A. (2008). Resistência de helmintos gastrintestinais de bovinos a anti-helmínticos no Planalto Catarinense. Ciência Rural, 38, 1363-1367. https://doi.org/10.1590/S0103-84782008000500026.

Stromberg, B E, \& Averbeck, G. A. (1999). The role of parasite epidemiology in the management of grazing cattle. International Journal for Parasitology, 29(1), 33-39. https://doi.org/10.1016/s00207519(98)00171-4.

Stromberg, Bert E, Gasbarre, L. C., Waite, A., Bechtol, D. T., Brown, M. S., Robinson, N. A., Olson, E. J., \& Newcomb, H. (2012). Cooperia punctata: effect on cattle productivity? Veterinary Parasitology, 183(3-4), 284-291. https://doi.org/10.1016/j.vetpar.2011.07.030.

Histórico do artigo:

Recebido: 23 de agosto de 2021

Aprovado: 1 de outubro de 2021

Disponível online: 11 de dezembro de 2021

\footnotetext{
Licenciamento: Este artigo é publicado na modalidade Acesso Aberto sob a licença Creative Commons Atribuição 4.0 (CC-BY 4.0), a qual permite uso irrestrito, distribuição, reprodução em qualquer meio, desde que o autor e a fonte sejam devidamente creditados.
} 